\title{
POLLINATOR EFFECTIVENESS IN THE MIXED-POLLINATION SYSTEM OF A NEOTROPICAL PROTEACEAE, OREOCALLIS GRANDIFLORA
}

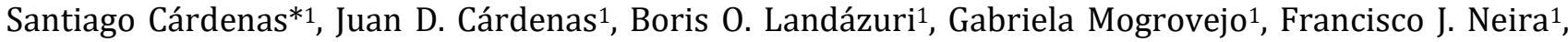 \\ Antonio M. Crespo ${ }^{1,2}$, Nils Breitbach ${ }^{3}$, Matthias Schleuning ${ }^{4}$, Boris A. Tinoco ${ }^{1}$ \\ ${ }^{1}$ Escuela de Biología, Universidad del Azuay, Av. 24 de Mayo 7-77 \& Hernán Malo, Cuenca, Ecuador \\ ${ }^{2}$ Laboratorio de Ecología y Manejo de Plantas Nativas, Universidad del Azuay, Av. 24 de Mayo 7-77 e Hernán Malo, Cuenca Ecuador \\ ${ }^{3}$ Proyecto Prometeo, SENESCYT, Av. 9 de Octubre N22-48 \& Gil Ramirez Dávalos, Casa Patrimonial, Quito, Ecuador \\ ${ }^{4}$ Senckenberg Biodiversity and Climate Research Centre, Seckenberganlage 25, 60325 Frankfurt, Germany
}

\begin{abstract}
In pollination systems with a diverse community of floral visitors, qualitative and quantitative variations in pollination effectiveness can lead to a system in which higher effectiveness results from the synergetic contribution of multiple pollinators. By employing a series of field and laboratory experiments in the south Andes of Ecuador, we compared the effectiveness of hummingbirds and nocturnal mammals visiting Oreocallis grandiflora, an Andean member of the Proteaceae. Pollinator effectiveness was measured with a quantitative component that assessed visitation rates to inflorescences and number of contacted stigmas per visit, and with a qualitative component based on the number of deposited pollen grains in stigmas. Effectiveness estimates were complemented with controlled pollination experiments that contrasted fruit and viable seed set among flowers exposed to either diurnal or nocturnal pollination, self-pollinated flowers, and a control group with flowers exposed to naturally occurring pollination. Six species of hummingbirds and two species of nocturnal mammals visited the flowers of $O$. grandiflora. Hummingbirds outperformed nocturnal mammals in the quantitative components of pollination, while mammals were more effective than hummingbirds in the qualitative component. Pollination success was higher for the control group than for the other treatments, while hummingbirds and mammals performed similarly. Our findings suggest a case of functional complementarity in pollination: hummingbirds' quantitative effectiveness complements nocturnal mammals' qualitative effectiveness. Furthermore, our study demonstrates that pollination success in plants can be greater when flowers are visited by the whole diversity of pollinators.
\end{abstract}

Keywords: Andes, Functional complementarity, pollination effectiveness, pollination success, Proteaceae, vertebrate pollination.

\section{INTRODUCTION}

The vast majority of angiosperms rely on a diversity of animal pollinators to successfully complete reproduction (Ollerton et al. 20II). Nonetheless, there is a large variation in the pollination performance as not all animal groups are equally effective at pollinating the plants they visit (Stebbins 1970; Padyšáková et al. 2013; Krauss et al. 2017). Although the development of quantitative frameworks to measure effectiveness of pollinators has provided important insights into the reproduction effects that result from the visit of a pollinator to a flower (e.g. Ne'Eman et al. 20I0; Schupp et al. 2017; Willcox et al. 2017), there is still much to learn about the factors influencing variations in effectiveness among pollinators, especially in areas of high diversity such as the tropical Andes. Comparing the effectiveness of pollinators from different functional and taxonomic groups, such as birds and mammals, can unveil key information about how different foraging behaviours, activity times and morphologies can determine the pollination performance of a pollinator. This

Received 25 January 2020, accepted I6 June 2020

*Corresponding author: scardenas@uazuay.edu.ec information is also crucial for a better understanding of the ecology and evolution of animals and plants that are part of pollination interactions (Gómez \& Zamora 2006; Schleuning et al. 2015; Armbruster 2017).

Many methods have been proposed to measure the effectiveness of pollinators (Ne'Eman et al. 2010; Schupp et al. 2017); however, the most common approaches focus on methods that partition effectiveness into quantitative and qualitative components (Herrera, 1987, 1989; Wilcox et al. 2017). The quantitative component usually measures the frequency of the interaction between a pollinator and a plant (e.g. visitation rates; Herrera 1987; Vázquez et al. 2015; Schupp et al. 2017), and the qualitative component measures the outcome of a pollinator visit (e.g. pollen deposition; Muchhala \& Thomson 2010; Dellinger et al. 2019, but see Herrera 1987, Schupp et al. 2017 for other aspects of measuring quality). When comparing pollination effectiveness among pollinators, differences may arise from variation in both components of effectiveness (e.g. Rodríguez-Rodríguez et al. 2013; Zych et al. 2013). For example, a pollinator that exhibits high visitation rates (quantitative component) may deposit a small number of pollen grains (qualitative component; Madjidian et al. 2008). In contrast, a pollinator may have low visitation rates but deposit a high number of pollen grains during each visit (Muchhala \& Thomson 2010). 
In this context, detailed estimates of pollinator performance, in quantitative and qualitative terms, are critical to the understanding of how effectiveness varies among different pollinators.

Moreover, although visitation-based methods are useful to compare the relative contribution of multiple pollinators to a commonly visited plant, they do not consider other factors that can influence pollination success (e.g. genetic quality of the pollen). Thus, measures of pollination effectiveness should be complemented by information about pollination success, such as fruit and seed set (Schupp et al. 2017; Willcox et al. 2017).

Pollination by vertebrates is widespread in the Neotropical region, with hummingbirds and bats recognized as the most important vertebrate groups (Bawa 1990; Fleming et al. 2009; Garibaldi et al. 20I I; Anderson et al. 2016). Birds and bats can be highly effective pollinators because they are active in variable environmental conditions (e.g. rain, variable temperature, day and night, etc.) and have relatively large home ranges that promote outcrossing among plants (Sahley 1996; Abe et al. 20II; Krauss et al. 2017). However, morphological and behavioural differences between hummingbirds and bats may result in contrasting contributions to the components of pollination effectiveness (Sahley 1996; Amorim et al. 2013; Aguilar-Rodríguez et al. 2016). For instance, hummingbirds can have higher floral visitation rates than bats (Queiroz et al. 2016), and thus be quantitatively more effective. Nonetheless, the fur in mammals could gather, hold and deposit more pollen grains in consecutive visits to flowers compared to the feathers of hummingbirds, resulting in qualitatively superior effectiveness (Muchhala \& Thomson 2010). Detailed studies comparing pollination effectiveness between hummingbirds and bats are still scarce in Neotropical regions (Muchhala et al. 2009; Aguilar-Rodríguez et al. 20I4).

Oreocallis grandiflora (Proteaceae) is an Andean shrub ideally suited to explore variations in pollination effectiveness among pollinators. It is a locally common species, with inflorescences available throughout the year, and is pollinated by different functional groups (Prance et al. 2007; Hazlehurst et al. 2016). In the southern Andes of Ecuador, O. grandiflora is visited by at least seven hummingbird species during day hours, and the bat Anoura geoffroyi during night hours (Hazlehurst et al. 2016). In addition, it was recently discovered that $O$. grandiflora is also visited by the Andean mouse, Microryzomys altissimus, during night hours (Cárdenas et al. 2017).

We used observations and field experiments to compare the quantitative and qualitative effectiveness of hummingbirds and nocturnal mammals as pollinators of $O$. grandiflora. We complemented effectiveness measures by assessing the pollination success of flowers visited by hummingbirds and mammals. We predicted that: I) hummingbirds would outperform mammals in the quantitative component; 2) mammals would outperform hummingbirds in the qualitative component. Within this context, we expected to find a similar pollination success in flowers of $O$. grandiflora visited by hummingbirds and mammals.

\section{MATERIALS AND METHODS}

\section{Study area}

The study was conducted in the Estación Científica El Gullán (320'I7.35" S, 79²10'I6.89" W), a research station owned and managed by Universidad del Azuay, located within the Azuay province in the southern Andes of Ecuador. El Gullán comprises 136 hectares, and covers an elevation range from 2,800 - 3,I00 $\mathrm{m}$ asl. There is a rainy season from October to April and a dry season from May to September. The total annual precipitation in the region averages $820 \mathrm{~mm}$ (Luna-Romero et al. 2018). The vegetation is high-elevation montane scrub. Representative plant species include Bejaria resinosa (Ericaceae), Bomarea glaucescens (Alstroemeriaceae), Hesperomeles obtusifolia (Rosaceae), Oreocallis grandiflora (Proteaceae), Pernettya prostrata (Ericaceae) and Viburnum triphyllum (Adoxaceae). Field work extended from August 2015 to July 2016.

\section{Study species}

Oreocallis grandiflora Lam. R.Br. (Proteaceae) is distributed from central Ecuador to southern Peru, across an elevation range from $\mathrm{I}, 000$ to $4,000 \mathrm{~m}$ asl (Prance et al 2007). It can be found among a variety of vegetation types, including montane forest, montane scrublands and high elevation elfin forest (Ulloa Ulloa \& Jørgensen I993; Homeier et al. 2008). It is typically a shrub, but some individuals can grow into trees up to $10 \mathrm{~m}$ in height.

O. grandiflora displays terminal inflorescences 7 to $38 \mathrm{~cm}$ in length, with flower colour and morphology varying among populations (Ulloa Ulloa \& Jørgensen 2004; Hazlehurst et al. 2016). In the studied population, the flower colour was uniformly creamy white (Fig. I). The flowers are protandrous, and male and female flowers are present simultaneously; tepals are connate and the style apex is modified into a disc-shaped, slightly conical pollen presenter that surrounds the stigma and faces up and away from the centre of the inflorescence (Fig. I). Anthesis occurs when tepals curve back to free the style apex/pollen presenter, which can happen during the day or night. Stigma receptivity lasts up to I5 days, and selfing can occur if pollen is left untouched on top of pollen presenters (personal observations). Nectar production continues throughout the day and night, with a mean 24 - hr nectar accumulation rate of $3 \mathrm{I} .7 \pm 3.5(S E) \mu \mathrm{l}$, and a mean sugar concentration of $27.8 \pm$ I.6 (SE) \% Brix (Hazlehurst et al. 2016). The main flowering season goes from March to June, although some flowers are available throughout the year.

\section{Field methods}

We explored differences in pollinator effectiveness between hummingbirds and nocturnal mammals by obtaining field data on the quantitative and qualitative components of pollination. The quantitative component comprised visitation rates to inflorescences and number of contacted stigmas per visit, whereas the qualitative component was based on the number of deposited pollen grains. Data on bats and mice were combined in a "nocturnal mammals" group. Insects rarely visit $O$. grandiflora inflorescences, and they do not seem to play a role in the pollination of this species (Hazlehurst et al. 2016; Cárdenas et al. 2017). 


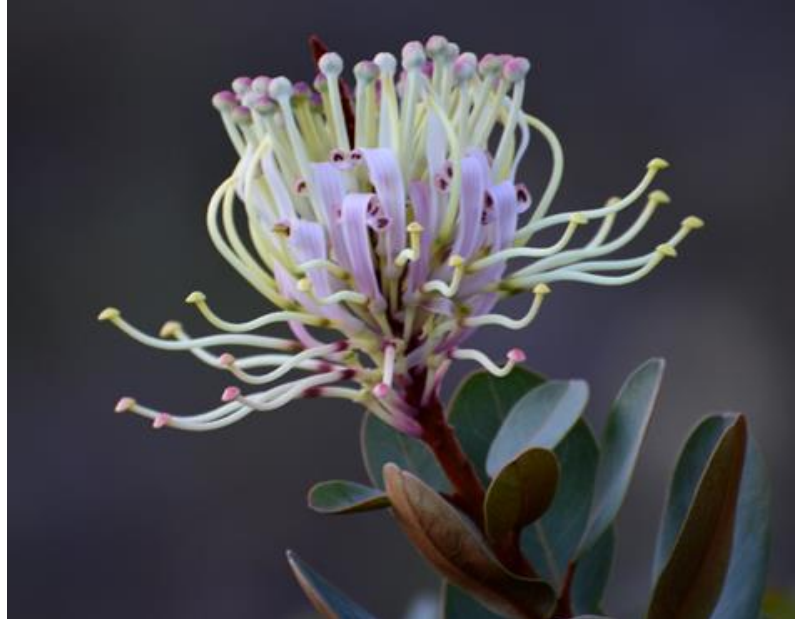

FIGURE I: An individual of Oreocallis grandiflora from the study area, detail of an inflorescence. Photo by Pedro Machado T.

\section{Quantitative component:}

\section{Floral visitation rate and number of contacted stigmas:}

Floral visits were recorded using video cameras during day and night hours on 152 separate inflorescences from I52 different plants. During the daytime we used 4 Sony Handycam DCR-SX45 cameras, each camera recording one inflorescence for ten hours. Recordings were done during two sampling periods, from 0600 to IIO0 h and from I200 to I700 h. The same inflorescences were sampled again during night-time with another set of 4 Bell \& Howell DNVI6HDZ night vision cameras equipped with infrared lights (Sony HVL-LEIRI). The night-time sampling hours were from 1900 to $2400 \mathrm{~h}$ and from $2400-0500 \mathrm{~h}$. Overall, we obtained 760 hours of day-time and 760 hours of night-time recordings.

The videos were manually processed to obtain two complementary measures of the quantitative component of pollination: Visitation rates to inflorescences and number of contacted stigmas. Visitation rate to inflorescences provides information about the potential number of pollinating visits. It was calculated as:

$$
R_{i}=\frac{V_{i}}{t}
$$

With:

$R_{i}=$ Visitation rate to inflorescence $i$

$V_{i}=$ Number of visits to inflorescence $i$

$t=$ Number of sampling hours

The number of contacted stigmas (single flowers) per visit is related to the behaviour of a given pollinator once a visit to an inflorescence occurs, and it was obtained for each visit of an animal to an inflorescence.

\section{Qualitative component}

\section{Number of deposited pollen grains:}

Small pieces of clear double-sided adhesive tape (ABRO Industries) were placed on top of stigmas in order to collect pollen grains transferred by pollinators during floral visits (Muchhala \& Thomson 2010). The pieces of adhesive tape were attached to the stigmas by pasting one end to the other, forming an adhesive loop around the pollen presenter. A total of 62I stigmas from 68 inflorescences and 34 plants were used (two inflorescences per plant). The number of stigmas sampled per inflorescence was based on the availability of flowers according to the following design:

- 4-8 stigmas exposed to hummingbird-pollination: Adhesive tape applied just before dawn and removed just before dusk.

- 4-8 stigmas exposed to nocturnal mammal-pollination: Adhesive tape applied just before dusk and removed just before dawn.

Because stigma receptivity in O. grandiflora can last for I5 days (personal obs.), pollen deposition was considered as a cumulative process (Padyšáková et al. 2013). After I2 hours of exposition, the adhesive pieces of tape were collected and pasted onto microscope slides. The number of pollen grains were counted using a microscope.

The number of deposited grains of pollen in stigmas containing pollen loads was calculated as:

$$
P_{i}=\frac{\mathrm{S}_{i}}{t}
$$

With:

$P_{i}=$ Deposited grains of pollen per stigma hour ${ }^{-1}$.

$S_{i}=$ Number of pollen grains collected in stigma $i$.

$t=$ Number of hours exposed.

\section{Pollination success}

To complement the information provided by the qualitative and quantitative components of effectiveness, an experimental exclusion study was done to measure pollination success by means of fruit set and seed set (Willcox et al. 2017). In order to explore more about the dependence of $O$. grandiflora to animal pollination, $O$. grandiflora inflorescences were exposed to four different experimental treatments:

- Exposure to hummingbird pollination: Inflorescences were exposed exclusively during day time hours and covered during night time hours.

- Exposure to nocturnal mammal pollination: Inflorescences were exposed during night time and covered during day time hours.

- Full exclusion from pollinators: Inflorescences were completely excluded during day and night to prevent any visit of pollinators. This treatment allowed us to measure fruit set under autogamy and compare it with animal pollination.

- Control: Inflorescences were left uncovered for the duration of the experiment; thus, they were available for pollinators during night and day. 
Each experimental treatment was maintained for I5 consecutive days corresponding to the stigma receptivity period. To cover inflorescences, we used a fine mesh, placed over a cage of light wire to avoid contact of the mesh with the flowers. The day the bagging process began, the number of open and budding flowers was quantified and marked using a cotton thread. In total, 27 pairs of neighbouring plants were used in this study. Each plant contained two inflorescences, each with one of two treatments; thus a pair of plants contained all four experimental treatments. Fruit (follicle) development was checked weekly for 28 weeks, and fruits were collected when dehiscence began.

\section{Fruit set:}

Fruit set per inflorescence was obtained by comparing the number of follicles produced to the overall number of flowers that were exposed to the four pollination treatments using the following relationship:

$$
F r=\left(\frac{N}{N_{f}}\right) \cdot 100
$$

With:

$F_{r}=$ Fruit set.

$N=$ Number of follicles.

$N_{f}=$ Number of flowers.

\section{$\underline{\text { Viable seed set: }}$}

To obtain information on the influence of the different pollinators on the production of viable seeds, we calculated seed set. Seeds were collected from a random sample of mature follicles resulting from the different exclusion treatments previously described. In total, 3,20I seeds were collected from 285 follicles. Seeds were classified according to embryonic development into 'viable' and 'non-developed'. Only seeds displaying a wide lateral and longitudinal section containing the developed embryo (i.e. swollen or wide seeds) were considered to be viable (Sánchez I99I; Schmidt 2000). This morphology-based classification was supported by the application of the Tetrazolium Chloride Test (TTZ) (Schmidt 2000) to a random sample of seeds: seeds tinted red were classified as viable, whereas seeds that were not tinted were classified as non-viable. Finally, viable seed set was calculated for each pollination exclusion treatment as:

$$
V=\left(\frac{S_{v}}{S_{t}}\right) \cdot 100
$$

With:

$V=$ Viable seed set

$S_{v}=$ Number of viable seeds

$S_{t}=$ Number of total seeds

After obtaining fruit set and viable seed set, we multiplied both variables $(\mathrm{Fr} \cdot V)$ in order to obtain a measure of pollination success as a function of both processes.

\section{Statistical analysis}

Statistical analyses were conducted in $\mathrm{R}$ version 3.5.2 ( $\mathrm{R}$ Core Team 2015). For all the models described below we employed the statistical package lme4 (Bates et al. 2015).

\section{Quantitative component}

We used generalised linear mixed effects models (GLMM) with Poisson distribution to explore differences among pollinators in visitation rates to inflorescences, and numbers of stigmas contacted per visit. In the model of visitation rates, the number of sampling hours was used as an offset (Yan et al. 2009). The monitoring date was used as a random factor in both models to control for potential autocorrelations resulting from flowers that were observed on the same day.

\section{Qualitative component}

To test for differences in the numbers of pollen grains deposited by hummingbirds and nocturnal mammals, a GLMM with Poisson distribution was used. An offset, accounting for the sampling effort, was used in the model. To account for the hierarchical structure of the data, in the random component of these models, we nested stigmas within inflorescences, and inflorescences within plants.

\section{Pollination success}

A linear mixed model (LMM) was used to determine the effects of experimental treatments on pollination success. The random term of the model was composed of inflorescences nested within plants, and plants nested within pairs of neighbouring plants.

\section{RESULTS}

\section{Quantitative component}

Eight species of vertebrates visited O. grandiflora flowers: six hummingbirds, one bat (Anoura geoffroyi) and one rodent (Microrizomys altissimus), in 760 hours of daytime recordings and 760 hours of night time recording (Tab. I). Behaviour during floral visitations varied among pollinators. Hummingbirds would perch or hover when feeding. Bats always hovered when feeding, and rodents handled flowers while feeding on nectar. Because of behavioural differences during flower visitation, body-to-pollen presenter contact was not consistent among pollinators (see Supplementary Material I).

Visitation rates to inflorescences were higher for hummingbirds $=0.8 \pm 0.17$ (mean $\pm S E$ ), than for mammals $=0.34 \pm 0.06$ (mean $\pm S E$; Fig 2, A; Tab. 2). Moreover, hummingbirds contacted $12.46 \pm 0.5$ (mean $\pm S E$ ) stigmas during a visit, significantly more than nocturnal mammals, which contacted $=7.94 \pm 0.56$ stigmas visit $^{-1}$ (mean $\pm S E$; Fig 2, B; Tab. 2).

\section{Qualitative component}

The number of pollen grains deposited differed significantly among pollinators ( Tab. 2). Nocturnal mammals deposited $2.27 \pm 0.3 \mathrm{I}$ pollen grains per flower $\mathrm{h}^{-1}$ (mean \pm $S E$ ), and hummingbirds deposited I.35 \pm 0.26 pollen grains per flower $h^{-1}$ (mean $\pm S E$; Fig. 2, C). 
TABLE I. List of vertebrate species visiting Oreocallis grandiflora flowers in the Estación Científica El Gullán, southern Ecuador. The number of visits to inflorescences in 760 hours during the day, and $760 \mathrm{~h}$ during night are listed for each species.

\begin{tabular}{lll}
\hline Activity time & Species names (Family) & Total number of visits \\
\hline Diurnal & Heliangelus viola (Trochilidae) & 124 \\
& Aglaeactis cupripennis (Trochilidae) & 94 \\
& Metallura tyrianthina (Trochilidae) & 38 \\
& Lesbia nuna (Trochilidae) & 7 \\
& Coeligena iris (Trochilidae) & 6 \\
& Lesbia victoriae (Trochilidae) & 3 \\
Nocturnal & Anoura geoffroyi (Phyllostomidae) & 271 \\
& Microryzomys altissimus (Cricetidae) & 22 \\
\hline
\end{tabular}

TABLE 2. Results of generalised linear mixed effects models testing for differences between pollinators in visitation rates to inflorescences, number of contacted stigmas per visit and number of deposited pollen grains between hummingbirds and nocturnal mammals. A linear mixed model tests the effects of different experimental treatment on pollination success (fruit set $\mathrm{x}$ viable seed set).

\begin{tabular}{|c|c|c|c|c|c|c|}
\hline & & Coefficient & SE & $\mathrm{p}$ & CI (low) & CI (high) \\
\hline \multicolumn{7}{|l|}{ Inflorescences visited per hour } \\
\hline & Hummingbirds (intercept) & -0.89 & 0.27 & $<0.0 \mathrm{I}$ & $-\mathrm{I} .44$ & -0.37 \\
\hline & Nocturnal mammals & -0.69 & 0.35 & 0.05 & -1.40 & 0.02 \\
\hline \multicolumn{7}{|l|}{ Number of contacted stigmas } \\
\hline & Hummingbirds (intercept) & 3 & 0.13 & $<0.0 \mathrm{I}$ & 2.44 & 2.97 \\
\hline & Nocturnal mammals & $-0.4 \mathrm{I}$ & 0.04 & $<0.0 \mathrm{I}$ & -0.49 & -0.33 \\
\hline \multicolumn{7}{|l|}{$\begin{array}{l}\text { Deposited pollen grains per } \\
\text { hour }\end{array}$} \\
\hline & Hummingbirds (intercept) & -0.42 & 0.16 & $0.0 \mathrm{I}$ & -0.83 & -0.33 \\
\hline & Nocturnal mammals & $\mathrm{I} .32$ & 0.66 & 0.04 & -0.52 & 0.63 \\
\hline \multicolumn{7}{|l|}{ Pollination success } \\
\hline & Control (Intercept) & 1.69 & 0.25 & $<0.0 \mathrm{I}$ & $1.2 \mathrm{I}$ & 2.17 \\
\hline & Full exclusion & -0.45 & 0.29 & 0.12 & $-\mathrm{I} .0 \mathrm{I}$ & $0 . \mathrm{II}$ \\
\hline & Hummingbirds & -0.63 & 0.33 & 0.06 & $-\mathrm{I} .27$ & 0.00 \\
\hline & Nocturnal mammals & -0.18 & 0.33 & 0.58 & -0.82 & 0.46 \\
\hline
\end{tabular}

\section{Pollination success}

The control group achieved higher success than the other experimental treatments; pollination success was $\mathrm{I} 0.09 \pm 2.3 \mathrm{I}$ (mean $\pm S E$ ) for the control group; $6.99 \pm 2.14$ (mean \pm $S E$ ), for full exclusion; $7.45 \pm 1.57$ (mean $\pm S E$ ) for nocturnal mammals; and $5.33 \pm 1.99$ (mean $\pm S E$ ) for hummingbirds (Fig. 3). However, no statistical differences were found among the different experimental treatments ( Tab. 2).

\section{DISCUSSION}

Estimates of pollination effectiveness deriving from different functional groups, such as the ones described in this study, can contribute to a better understanding of communitylevel dynamics in tropical ecosystems. For our study species, Oreocallis grandiflora, we found that hummingbirds outperformed nocturnal mammals in the quantitative component of pollination effectiveness, while nocturnal mammals where more effective than hummingbirds in the qualitative component. Exploring pollination success, we found that flowers pollinated by either hummingbirds or mammals had similar outcomes, while there was indication that pollination success could increase in flowers exposed to both pollinator groups. Overall, these results suggest a functional complementary role of hummingbirds and mammals as pollinators of $O$. grandiflora.

Visitation rates to inflorescences and number of stigmas contacted per visit indicated that hummingbirds were more effective than mammals in the quantitative component of pollination. Differences in abundance between nectarivorous bats and hummingbirds could result in hummingbirds having higher visitation rates to inflorescences. However, we have no density estimates of hummingbirds and mammals in our study area to confirm this hypothesis. Physiological differences between hummingbirds compared to nocturnal mammals, may also lead to the higher visitation rates by hummingbirds. 
Quantitative component

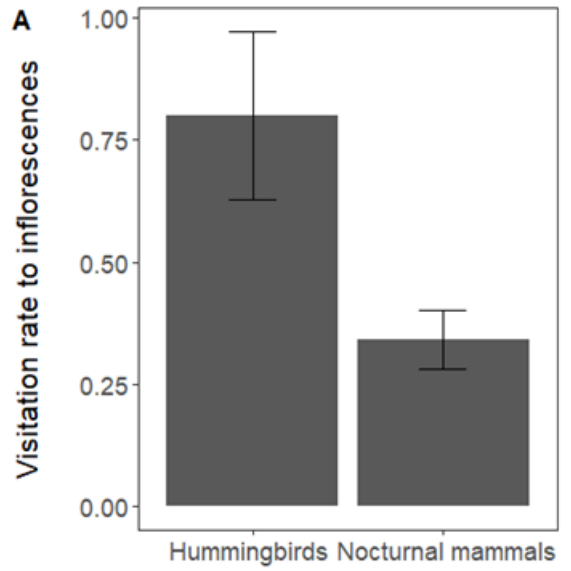

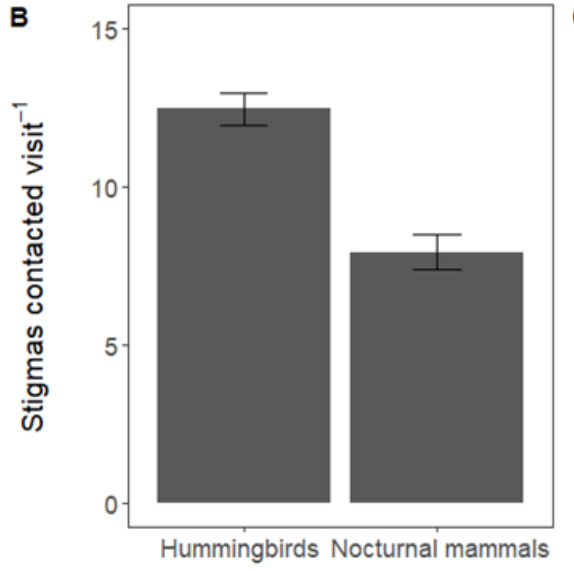

Qualitative component

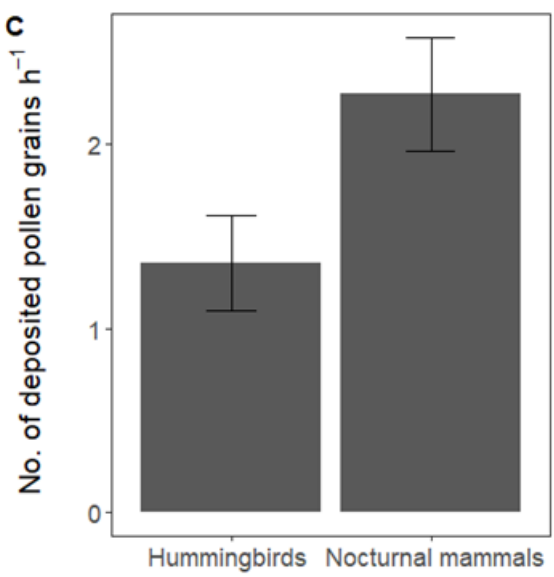

FIGURE 2: Values of the effects of different pollinators on quantitative and qualitative subcomponents of pollination of Oreocallis grandiflora. Values depicted are mean $\pm S E$. Different letters above the $S E$ bars indicate statistical differences.

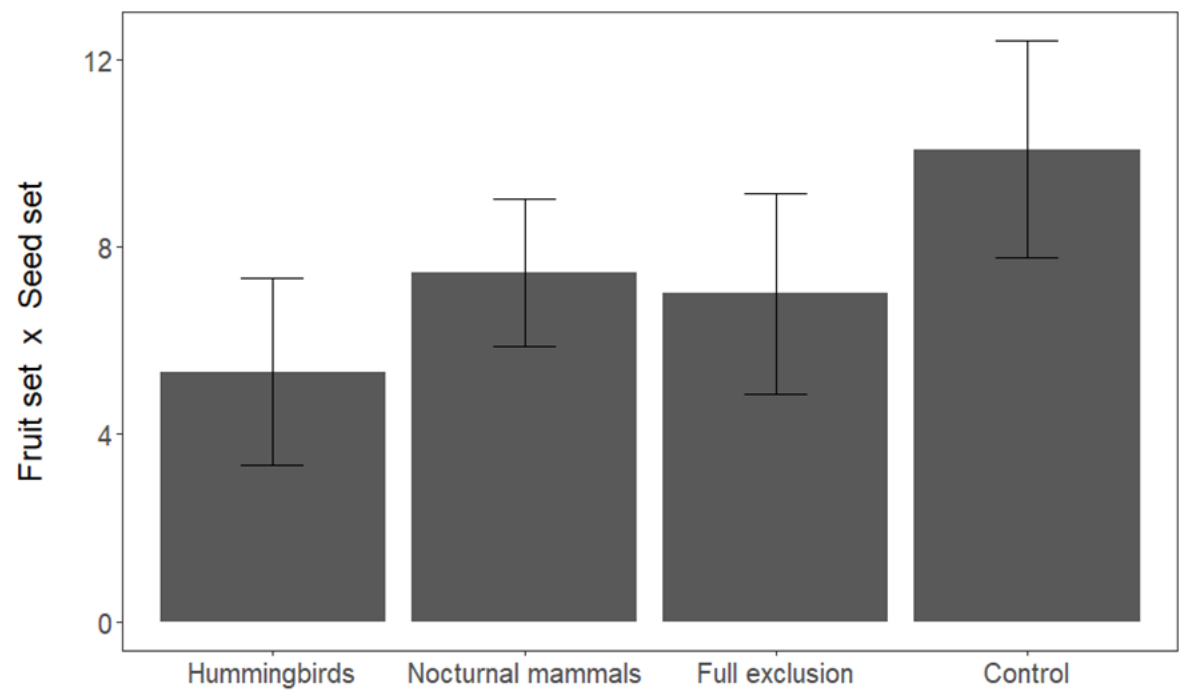

FIGURE 3: Pollination success of Oreocallis grandiflora after flowers were exposed to different pollination treatments: flowers exposed to hummingbird pollination, flowers exposed to nocturnal mammal pollination, flowers fully excluded from pollination, and control group of flowers available for all pollinators. All values are means \pm I $S E$.
Hummingbirds and nectivorous bats need to constantly feed during their activity periods to satisfy their energetic demands (Chittka \& Thomson 200I; Altshuler et al. 2004; McCallum et al. 2013); however, due to their smaller body size, hummingbirds store less energy than nectarivorous bats, and therefore, hummingbirds need to feed more frequently than larger mammals (McCallum et al. 2013).

The variation in the number of stigmas contacted per visit between hummingbirds and mammals might be related to behavioural differences and the morphological fit between flowers and the bodies of pollinators (see Supplementary Material I). Hummingbirds are able to perform complex manoeuvres in flight (Tobalske et al. 2004; Dakin et al. 2020), and are able to touch multiple stigmas in a single visit, either by hovering from flower to flower or by perching in styles of flowers. In the case of nocturnal mammals, bats showed swift visits to inflorescences, where they hovered in front of flowers and touched a limited number of stigmas before leaving. Mice climbed around the centre of the inflorescence until reaching a flower with nectar, but their bodies missed most stigmas located in the extremes of the extended styles of $O$. grandiflora flowers (Hazlehurst et al. 2016).

The result of mammals outperforming hummingbirds in the qualitative component of pollination is similar to what has been found elsewhere (Muchhala et al. 2009). Fur on mammals can store and retain pollen more efficiently than feathers on birds (Muchhala \& Thomson 2010), resulting in mammals being more effective in transporting and transferring pollen than hummingbirds (Muchhala 2003; Muchhala et al. 2009). However, pollination effectiveness in the qualitative component is usually measured as per visit effectiveness (Herrera 1987; Schupp et al. 2017). Due to practical limitations we could not use that method, and instead obtained data on number of pollen grains accumulated during the $\mathrm{I} 2$ hours of each sampling period. Nonetheless, if we were to assess pollen deposition per visit our conclusions should not change. Stigmas were exposed during the same number of 
hours for each pollinator group, and according to our results in the quantitative component, hummingbirds visit flowers more frequently than mammals over time. The higher effectiveness of mammals in the qualitative component was very likely a result of mammals depositing more pollen grains per visit. However, it will be interesting to incorporate other measures of pollination quality to our study system, such as the ratio of heterospecific and homospecific pollen deposition. Moreover, the finding that hummingbirds visited more flowers within inflorescences than mammals, indicates that potentially they transfer more geitonogamous pollen to flowers, thus $O$. grandiflora could be an ideal system to study differences in the genetic diversity of pollen transferred by different animal pollinator groups. Lastly, it is important to mention that our estimates of pollinator performance are focused only in the female phase, related to pollen reception, and do not consider the male phase of pollination, which accounts for pollen removal (Thomson 2003). Differences in male phase effectiveness among pollinators can have effects on fitness (Muchhala \& Thomson 2012; Konzmann et al. 2020), and future studies in $O$. grandiflora should incorporate measures of pollen transfer efficiency to complement our findings.

Functional complementarity of pollination occurs when the performance of two or more animal pollinators results in higher fitness of the plant they pollinate compared to the fitness obtained by the pollination of single species or animal group (Blüthgen \& Klein 20II). Our exclusion experiments indicated that pollination success, a proxy for fitness, was $\sim 2$ times higher when $O$. grandiflora flowers were pollinated by hummingbird and bats rather than by any group alone; thus, hummingbirds and bats can have synergetic effects on pollination as a form of functional complementarity. Niche partitioning in daytime activity periods can commonly result in such ecological complementarity among pollinators (Dar et al. 2006). In this case, temporal niche partitioning in $O$. grandiflora pollinators likely enhances reproductive success by allowing pollination to happen during day and night. Functional complementarity in the different components of pollination could be a potential mechanism explaining the positive effects of biodiversity in pollination success.

The functional complementarity of hummingbirds and nocturnal mammals could be facilitated by the floral architecture of $O$. grandiflora which presents open flowers with little physical restrictions to access nectar. The shape of its flowers allows large-bodied pollinators to feed on nectar while contacting reproductive organs. Additionally, nectar production in O.grandiflora is constant in both concentration and volume during day and night time hours (Hazlehurst et al. 2016), allowing hummingbirds and nocturnal mammals to feed on nectar during their regular activity periods. Likewise, sucrose concentration in nectar from $O$. grandiflora, fits within the range preferred by hummingbirds (Bolten \& Feinsinger 1978; Tamm \& Gass 1986; Fleming et al. 2005), and bats of the genus Anoura (Herrera 1999).

The high levels of pollination success that resulted from self-pollination may indicate a generalized pollination system in O. grandiflora. Once anthesis has occurred in its flowers, cross-pollination relies on a pollinator to 'dust pollen off from pollen presenters before receptivity begins (personal observation). In the absence of pollinators, as was the case in our experimental treatment that fully excluded crosspollination, pollen remained in pollen presenters and when the presenters matured to become receptive stigmas, the flowers self-pollinated. High levels of self-pollination have also been reported in other Proteaceae species (Ayre et al. 1994). However, our results differ from a similar experiment with $O$. grandiflora performed in Peru where self-pollination resulted in lower seed set compared to cross-pollinated flowers (Hazlehurst et. al 2016). Thus, more studies are needed to explore the effects of outcrossing rates on the fitness of $O$. grandiflora plants.

Our study of pollination performance of vertebrates in a mixed-pollination system contributes to a better understanding of the factors that influence variation in the pollination effectiveness of hummingbirds and bats. Our results suggest a negative quality and quantity correlation among pollination components where hummingbirds can be more effective than mammals in the quantitative component, while mammals perform better than hummingbirds in the qualitative component. Lastly, we show that hummingbirds and nocturnal mammals have functional complementary roles in pollination, demonstrating the importance of biodiversity for the maintenance of key ecosystem functions (Loreau et al. 200I; Schleuning et al. 20I5).

\section{ACKNOWLEDGEMENTS}

Field work for this project was assisted by students from Universidad del Azuay. We would also like to thank Jacinto Guillén, Head of the Research Department at Universidad del Azuay, Carlos Nivelo, Pedro Machado and Gabriel Malo. This work was conducted with a research grant from Vicerrectorado de Investigaciones, Universidad del Azuay (project code 2016-35 \& 2017-II), and PROMETEO-SENESCYT program.

\section{APPENDICES}

Additional supporting information may be found in the online version of this article:

APPENDIX I. Video of different pollinators visiting Oreocallis grandiflora.

\section{REFERENCES}

Abe H, Ueno S, Tsumura Y, Hasegawa M (20II) Expanded Home Range of Pollinator Birds Facilitates Greater Pollen Flow of Camellia japonica in a Forest Heavily Damaged by Volcanic Activity. In: Isagi Y, Suyama Y (eds) Single-Pollen Genotyping. Springer Japan, Tokyo, pp 47-62.

Aguilar-Rodríguez PA, Krömer T, García-Franco JG, Macswiney G. MC (2016) From dusk till dawn: Nocturnal and diurnal pollination in the epiphyte Tillandsia heterophylla (Bromeliaceae). Plant Biology I8:37-45.

Aguilar-Rodríguez PA, MacSwiney G MC, Krömer T, GarcíaFranco JG, Knauer A, Kessler M (2014) First record of batpollination in the species-rich genus Tillandsia (Bromeliaceae). Annals of botany II3:1047-55.

Altshuler DL, Dudley R, McGuire JA (2004) Resolution of a paradox: Hummingbird flight at high elevation does not come without a cost. Proceedings of the National Academy of Sciences I0I:I773I-I7736 
Amorim FW, Galetto L, Sazima M (2013) Beyond the pollination syndrome: Nectar ecology and the role of diurnal and nocturnal pollinators in the reproductive success of Inga sessilis (Fabaceae). Plant Biology 15:317-327.

Anderson SH, Kelly D, Robertson AW, Ladley JJ (2016) Pollination by Birds: A Functional Evaluation. In: Sekercioglu ÇH, Wenny DG, Whelan CJ (eds) Why Birds Matter? University of Chicago Press, pp 73-106.

Armbruster WS (2017) The specialization continuum in pollination systems: diversity of concepts and implications for ecology, evolution and conservation. Functional Ecology 3I:88-I00.

Ayre DJ, Whelan RJ, Reid A (1994) Unexpectedly high levels of selfing in the Australian shrub grevillea barklyana (Proteaceae). Heredity 72:168-174.

Bates D, Mächler M, Bolker B, Walker S (2015) Fitting Linear Mixed-Effects Models using lme4. 67

Bawa KS (1990) Plant-Pollinator Interactions In Tropical Rain Forests. Annual Review of Ecology and Systematics 2I:399-422.

Blüthgen N, Klein AM (201I) Functional complementarity and specialisation: The role of biodiversity in plant-pollinator interactions. Basic and Applied Ecology 12:282-29I.

Bolten AB, Feinsinger P (1978) Why Do Hummingbird Flowers Secrete Dilute Nectar? Biotropica 10:307-309.

Cárdenas S, Nivelo-Villavicencio C, Cárdenas JD, Omar Landázuri P, Tinoco BA (2017) First record of flower visitation by a rodent in Neotropical Proteaceae, Oreocallis grandiflora. Journal of Tropical Ecology 33:174-177.

Chittka L, Thomson JD (Eds) (200I) Cognitive Ecology of Pollination. Cambridge University Press, Cambridge.

Dakin R, Segre PS, Straw AD, Altshuler DL (2020) Morphology, muscle capacity, skill, and maneuvering ability in hummingbirds. Science 657:653-657.

Dellinger AS, Chartier M, Fernández-Fernández D, Penneys DS, Alvear M, Almeda F, Michelangeli FA, Staedler Y, Armbruster WS, Schönenberger J (2019) Beyond buzz-pollination departures from an adaptive plateau lead to new pollination syndromes. New Phytologist 22I:I I36-I I49.

Fleming TH, Geiselman C, Kress WJ (2009) The evolution of bat pollination: A phylogenetic perspective. Annals of Botany I04:1017-I043.

Fleming TH, Muchhala N, Ornelas JF (2005) New World nectarfeeding vertebrates: community patterns and processes. In: Sánchez-Cordero V, Medellín RA (eds) Contribuciones mastozoológicas en homenaje a Bernardo Villa. Instituto de Biología, UNAM; Instituto de Ecología, UNAM; CONABIO, México, pp I63-I86.

Garibaldi LA, Muchhala N, Motzke I, Bravo-Monroy L, Olschewski R, Klein A-M (20II) Services from Plant-Pollinator Interactions in the Neotropics. In: Rapidel B, DeClerck F, Le Coq JF, Beer J (eds) Ecosystem services from agriculture and agroforestry: measurement and payment. Taylor and Francis, London, pp II9I40.

Gómez JM, Zamora R (2006) Ecological factors that promote the evolution of generalization in pollination systems. In: Waser NM, Ollerton J (eds) Plant-Pollinator Interactions. From specialization to generalization. The University of Chicago Press, Chicago, pp I45-I66.

Hazlehurst J, Tinoco BA, Cárdenas S, Karubian J (2016) Pollination ecology of Oreocallis grandiflora (Proteaceae) at the northern and southern ends of its geographic range. Journal of Pollination Ecology 19:7I-80.
Herrera CM (1987) Components of Pollinator "Quality": Comparative Analysis of a Diverse Insect Assemblage. Oikos 50:79-90.

Herrera CM (1989) Pollinator abundance,morphology,and flower visitation rate:analysis of the "quantity" component in a plantpollinator system. Oecologia 80:24I-248.

Herrera LG (1999) Preferences for Different Sugars in Neotropical Nectarivorous and Frugivorous Bats. Journal of Mammalogy 80:683-688.

Homeier J, Werner FA, Gradstein SR, Breckle SW, Richter M (2008) Potential Vegetation and Floristic Composition of Andean Forests in South Ecuador, with a Focus on the RBSF. In: Beck E Bendix J, Kottke I, Makeschin F, Mosandl R (eds) Gradients in a Tropical Mountain Ecosystem of Ecuador. Springer Berlin Heidelberg, Berlin, Heidelberg, pp 87-I00.

Konzmann S, Kluth M, Karadana D, Lunau K (2020) Pollinator effectiveness of a specialist bee exploiting a generalist planttracking pollen transfer by Heriades truncorum with quantum dots. Apidologie 5I:20I-2II.

Krauss SL, Phillips RD, Karron JD, Johnson SD, Roberts DG, Hopper SD (2017) Novel Consequences of Bird Pollination for Plant Mating. Trends in Plant Science 22:395-4IO. [online] URL: http://dx.doi.org/I0.10I6/j.tplants.2017.03.005

Loreau M, Naeem S, Inchausti P, Bengtsson J, Grime JP, Hector A, Hooper DU, Huston MA, Raffaelli D, Schmid B, Tilman D, Wardle DA (200I) Ecology: Biodiversity and ecosystem functioning: Current knowledge and future challenges. Science 294:804-808.

Madjidian JA, Morales CL, Smith HG (2008) Displacement of a native by an alien bumblebee: Lower pollinator efficiency overcome by overwhelmingly higher visitation frequency. Oecologia I56:835-845.

McCallum KP, McDougall FO, Seymour RS (2013) A review of the energetics of pollination biology. Journal of Comparative Physiology B: Biochemical, Systemic, and Environmental Physiology 183:867-876.

Muchhala N (2003) Exploring the boundary between pollination syndromes: Bats and hummingbirds as pollinators of Burmeistera cyclostigmata and B. tenuiflora (Campanulaceae). Oecologia I34:373-380,

Muchhala N, Caiza A, Vizuete JC, Thomson JD (2009) A generalized pollination system in the tropics: Bats, birds and Aphelandra acanthus. Annals of Botany I03:I48I-I487.

Muchhala N, Thomson JD (2010) Fur versus feathers: pollen delivery by bats and hummingbirds and consequences for pollen production. The American naturalist 175:717-26.

Muchhala N, Thomson JD (2012) Interspecific competition in pollination systems: Costs to male fitness via pollen misplacement. Functional Ecology 26:476-482.

Ne'Eman G, Jürgens A, Newstrom-Lloyd L, Potts SG, Dafni A (2010) A framework for comparing pollinator performance: Effectiveness and efficiency. Biological Reviews 85:435-45I.

Ollerton J, Winfree R, Tarrant S (20II) How many flowering plants are pollinated by animals? Oikos I20:32I-326.

Padyšáková E, Bartoš M, Tropek R, Janeček Š (2013) Generalization versus Specialization in Pollination Systems: Visitors, Thieves, and Pollinators of Hypoestes aristata (Acanthaceae). PLoS ONE 8:I-8.

Prance GT, Plana V, Edwards KS, Pennington RT (2007) Proteaceae. Flora Neotropica Monograph 100:250.

Queiroz JA, Quirino ZGM, Lopes A V., Machado IC (2016) Vertebrate mixed pollination system in Encholirium spectabile: A 
bromeliad pollinated by bats, opossum and hummingbirds in a tropical dry forest. Journal of Arid Environments I25:2I-30.

Rodríguez-Rodríguez MC, Jordano P, Valido A (2013) Quantity and quality components of effectiveness in insular pollinator assemblages. Oecologia 173:179-190.

Sahley CT (1996) Bat and hummingbird pollination of an autotetraploid columnar cactus, Weberbauerocereus weberbaueri (Cactaceae). American Journal of Botany 83:1329-1336.

Sánchez D (I99I) Formación y Desarrollo de las Semilla. In: Castillo R, Estrella J, Tapia C (eds) Técnicas para el manejo y uso de los recursos fitogenéticos, Ist edn. Quito, pp 88-96.

Schleuning M, Fründ J, García D (2015) Predicting ecosystem functions from biodiversity and mutualistic networks: An extension of trait-based concepts to plant-animal interactions. Ecography 38:380-392.

Schmidt LH (2000) Seed Testing. In: Guide ot Handling of Tropical and Subtropical Forest Seed. Danida Forest Seed Centre, Humlebaek, pp 28I-322.

Schupp EW, Jordano P, Gómez JM (2017) A general framework for effectiveness concepts in mutualisms. Ecology Letters 20:577-590.

Stebbins GL (1970) Adaptive Radiation of Reproductive Characteristics in Angiosperms, I: Pollination Mechanisms. Annual Review of Ecology and Systematics I:307-326.

Tamm S, Gass CL (1986) Energy intake rates and nectar concentration preferences by hummingbirds. Oecologia 70:20-23.
Thomson J (2003) When Is It Mutualism? The American Naturalist I62:SI-S9.

Tobalske BW, Altshuler DL, Powers DR (2004) Take-off mechanics in hummingbirds (Trochilidae). Journal of Experimental Biology 207:I345-I352.

Ulloa Ulloa C, Jørgensen PM (1993) Árboles y arbustos de los Andes del Ecuador. Aarhus University (in association with the Pontificia Universidad Catolica, Quito, Ecuador)., Aarhus, Denmark.

Ulloa Ulloa C, Jørgensen PM (2004) Oreocallis R. Br. Trees and shrubs of the Andes of Ecuador: eFloras.org

Vázquez DP, Ramos-Jiliberto R, Urbani P, Valdovinos FS (2015) A conceptual framework for studying the strength of plant-animal mutualistic interactions. Ecology Letters I8:385-400.

Willcox BK, Aizen MA, Cunningham SA, Mayfield MM, Rader R (2017) Deconstructing pollinator community effectiveness. Current Opinion in Insect Science 2I:98-104.

Yan J, Guszcza J, Flynn M, Wu CP (2009) Applications of the Offset in Property-Casualty Predictive Modeling. CAS Forum:366-385.

Zych M, Goldstein J, Roguz K, Stpiczyńska M (2013) The most effective pollinator revisited: Pollen dynamics in a spring-flowering herb. Arthropod-Plant Interactions 7:315-322. 